\title{
O arquivamento da memória televisiva em plataformas de aplicativos digitais
}

\section{Archiving television memory on digital application platforms}

Paulo Eduardo Silva Lins Cajazeira ${ }^{1}$ e José Jullian Gomes de Souza ${ }^{2}$

Pós-doutorado em Ciências da Comunicação pela Universidade da Beira Interior, Portugal. Doutor em Comunicação e Semiótica pela PUC-SP. Mestre em Comunicação e Linguagens, UTP. Bacharel em Jornalismo pela PUC-PR. Professor associado do curso de Jornalismo e do Programa de Pós-Graduação em Biblioteconomia na Universidade Federal do Cariri (UFCA), Ceará. Líder do grupo de pesquisa Centro de Estudos e Pesquisa em Jornalismo (CEPEJor/UFCA/CNPq). E-mail: paulo.cajazeira@ufca.edu.br 


\section{Resumo}

O artigo propõe-se a fazer apontamentos iniciais acerca dos estudos sobre televisão por meio de uma conjectura pouco evidenciada no campo científico: o processo de arquivamento, salvaguarda e memória audiovisual televisiva sob as potencialidades das plataformas de aplicativos digitais. Apresenta-se como objetivo geral refletir sobre novas formas de arquivamento da memória audiovisual a partir da descrição da plataforma Globoplay. O estudo ocorre mediante uma investigação e reflexão inicial sobre o uso dessa plataforma digital como recurso e possibilidade de armazenamento, recuperação e disponibilização da produção audiovisual em âmbito televisivo, em diálogo com o cenário atual da ecologia midiática. Assim, o aplicativo Globoplay é identificado como lugar de memória digital, instantânea e móvel fortalecendo o vínculo entre o produto audiovisual, a televisão e o usuário/telespectador. A metodologia é de natureza qualitativa e perpassa um estudo descritivo sobre as possibilidades da plataforma para o arquivamento audiovisual em ambientes multiplataformas. Apontam-se como resultados as múltiplas interações entre as plataformas audiovisuais do Grupo Globo, o resgate de produtos audiovisuais armazenados em seu centro de arquivo e as novas formas de arquivamento sob o uso das potencialidades dos aplicativos digitais na internet.

Palavras-chave

Televisão, memória, arquivamento, aplicativo digital.

\section{Abstract}

The article proposes to make initial notes about studies on television from a conjecture little evidenced in the scientific field: the process of archiving, safeguarding and television audiovisual memory under the potential of digital application platforms. The general objective is to reflect on new ways of archiving audiovisual memory from the description of the Globoplay platform. The study takes place through an initial investigation and reflection on the use of this digital platform as a resource and the possibility of storing, retrieving and making available the audiovisual production produced on television, in dialogue with the current scenario of media ecology. Thus, the Globoplay 
application identified as a place of digital, instant and mobile memory, strengthening the link between the audiovisual product, television and the user / viewer. The methodology is qualitative in nature and runs through a descriptive study on the possibilities of the platform for audiovisual archiving in multiplatform environments. The results point to the multiple interactions between Grupo Globo's audiovisual platforms, the rescue of audiovisual products stored in its archive center and the new forms of archiving under the potential of digital applications on the internet. What corroborates to visualize a changing scenario, facing the ecosystem under construction of the new audiovisual media ecology.

\section{Keywords}

Television, memory, archiving, digital application.

O título deste artigo coloca em questão a necessidade da realização de estudos sobre a televisão frente a uma proposição não muita evidenciada no âmbito científico: seu processo de arquivamento, salvaguarda e memória audiovisual televisiva sob as potencialidades das plataformas de aplicativos digitais. No ano em que a televisão comemora seu aniversário de 70 anos no Brasil, tornase fundamental ratificar a reflexão sobre essa relação não somente diante do caráter tecnológico, que ressalta aos olhos numa primeira leitura, mas destacar a necessidade de compreensão do processo de construção memorialístico da imagem televisiva enquanto objeto da história, cultura, costumes e épocas passadas da sociedade e do meio de comunicação, que ainda se configura como um dos principais no país.

De acordo a Pesquisa Brasileira de Mídia (2016), 77\% da população assiste televisão sete dias por semana, $47 \%$ de segunda a sexta, e $27 \%$ preferem assistir somente aos sábados e domingos. Em relação ao acesso à internet, 38\% da população utiliza a rede durante sete dias por semana, sendo que $91 \%$ acessa pelo celular e $12 \%$ utilizam o tablet como dispositivo de acesso; e, dentre os usos da internet, 19\% disseram assistir TV. Esses dados corroboram para explicitar 
o papel de destaque da televisão brasileira e o crescimento, ainda que limitado, da internet e do uso da internet para assistir televisão.

Com o crescimento das mídias digitais, colaboração da internet e suas ferramentas e potencialidades, a televisão tem se adaptado ao novo cenário multiplataforma, crossmedia e transmidiático no novo ecossistema midiático da contemporaneidade, tendo como um dos produtos protagonistas o audiovisual. Nesse ecossistema, os "[...] meios e ambientes geram novas e variadas relações resultantes de sua natureza instável, móvel e global, gerando um constante estado de desequilíbrio que rapidamente se reequilibra para logo se desequilibrar novamente" (CANAVILHAS, 2010, p. 2, grifo nosso) e inserem o telespectador/ usuário numa nova dinâmica, assim como os processos de arquivamento e acesso à memória audiovisual da televisão nos ambientes digitais.

Compreende-se, então, que o armazenamento, acesso e difusão do conteúdo audiovisual da TV é reconfigurado pela interação digital, mobilidade e ubiquidade das mídias como forma de se aumentar a audiência e de se fazer presente em mais de um ambiente midiático. O mesmo processo ocorre com a memória, ressignificada sob a introdução tecnológica digital cujo uso e acesso ocorre perante também pelos dispositivos móveis, aplicativos digitais e serviços de streaming audiovisuais. Há uma expansão das possibilidades de armazenamento e acesso à memória televisual, reconfigurando as relações dos sujeitos com a memória audiovisual arquivada em aplicativos digitais e serviços de streaming, tais como o Globoplay.

O arquivo audiovisual é um objeto relativamente pouco explorado e, assim, uma reflexão sobre o uso de plataformas de aplicativos digitais como forma de propor o arquivamento audiovisual da televisão para além de um modelo de negócio surge num momento oportuno para que outros pesquisadores possam se debruçar sobre essa possibilidade de estudo, identificação e compreensão desse campo do conhecimento. Diante disso, o artigo se apresenta como uma reflexão inicial, objetivando olhar para a memória televisiva e os processos de arquivamento digital. 
Assim, conforme Rossini e Silva (2009, p. 31), "a maior parte desse material visual produzido está ligado à necessidade de registrar, preservar, reproduzir e identificar pessoas, objetos, lugares ou classes de dados visuais". Uma vez que esse material funciona como dispositivo de acesso às lembranças, ao passado, à visualização de outras épocas, ainda que sejam retratadas por programas ficcionais cujo intuito é retratar um tempo e história específicos. O objetivo geral, portanto, é refletir sobre novas formas de arquivamento da memória audiovisual por meio da descrição da plataforma Globoplay. Além disso, o artigo pretende identificar as transformações ocasionadas pela ecologia das mídias em diálogo com o campo audiovisual televisivo; descrever os usos da plataforma Globoplay para o arquivamento e acesso à memória televisual; e explicitar a importância do processo de arquivamento audiovisual no ambiente digital e multiplataforma.

\section{Os efeitos da ecologia midiática no cenário audiovisual}

Em permanente construção e desconstrução, o ambiente midiático transita por mudanças e alterações como parte de um processo de reconfiguração natural. As transformações são inevitáveis e beiram as mudanças positivas e negativas num ciclo infinito. Esse cenário é observado na proposta da ecologia das mídias, tendo como seus representantes Marshall McLuhan (1911-1980), Walter Ong (1912-2003) e Neil Postman (1931-2003), que em meados dos anos 1960 buscaram compreender as mudanças dos fenômenos midiáticos enfatizando a importância do ambiente em detrimento do conteúdo apresentado.

Na ecologia das mídias o protagonismo é dado ao ambiente e suas transformações, advindas da relação entre tecnologia e sociedade. Como explicita Postman (1994, p. 29, grifo nosso):

A ecologia da mídia investiga a questão de como os meios de comunicação afetam a percepção, a compreensão, os sentimentos e valores humanos. A palavra ecologia implica no estudo de ambientes: sua estrutura, conteúdo e impacto sobre as pessoas. Um ambiente é, afinal de contas, um sistema de mensagens complexo que impõe aos seres humanos certas maneiras de pensar, sentir e se comportar. 
Nesse emaranhado complexo ao qual pertence o ambiente midiático e no qual os sujeitos estão inseridos - sejam produtores ou consumidores -, observa-se uma nova movimentação, transformação e adaptação dos processos, produtos e formas de produção, disponibilização, uso e consumo. Essas mudanças ocorrem em conjunto com os processos de mobilidade e ubiquidade das telas, propiciados pelas expansão da cultura tecnológica, transformando os processos de arquivamento e memória dos produtos audiovisuais em ambientes digitais.

Acerca da mobilidade, Lemos e Josgrilberg (2009) corroboram a relação cada vez mais próxima entra a televisão e os aparelhos celulares, destacando como eixo de ligação o acervo de conteúdo. Tal apontamento, realizado em 2009 pelos autores, já salientava essa relação que vem se confirmando com a realidade midiática mundial: os meios de comunicação estão convergindo, assim como os fetiches tecnológicos e a presença de grandes acervos e bancos de dados digitais. Os efeitos desse processo? Tem-se um mundo cada vez mais configurado pelos ambientes, mas não de modo isolado em que cada mídia produz conteúdos individualmente. Ao invés disso, tem-se um panorama de contribuição, narrativas transmidiáticas e espalhamento do conteúdo pelas diversas telas globais. Com isso,

[...] no momento em que celulares começam a conectar com a internet e oferecem algumas de suas funções - livros, jornais, revistas, conversas por texto ao vivo ou não, telefonia, videoconferências, rádios, gravação de músicas, fotografia, televisão - o celular se torna uma casa remota para comunicações, uma casa móvel, um pocket hearth, um meio de viagem da mídia (LEVINSON, 2004, p. 53).

É um efeito também provocado pela ubiquidade do campo audiovisual e televisivo diante do "restabelecimento das condições de existência da televisão" (SERRA; SÁ; SOUZA FILHO, 2015, p. 4), que se configura como mais um desafio da atualidade, pois ao passo que a televisão mantém sua onipresença - como mostram os dados da Pesquisa Brasileira de Mídia - , a internet desponta na ecologia das mídias como um novo meio que vem adquirindo popularidade e potencial. Nessa perspectiva, a apresentação inicial de Jost (2015, p. 9) falava 
sobre o fim da televisão com o advento das novas tecnologias digitais, ou "pelo menos, à televisão como a conhecíamos nas últimas décadas: uma instituição com programas e conteúdos capaz de reunir o máximo de pessoas possível em torno de um único ecrã [tela]". O que se percebe que é de fato a televisão vem sendo modificada e a tela em que os primeiros telespectadores, na década de 1950, puderam ver as imagens iniciais junto com Assis Chateaubriand tem se transformado a partir do fenômeno da ubiquidade televisiva, da sua relação com a internet e da multiplicação e miniaturização das telas.

Esses são aspectos que se relacionam também à ideia de arquivamento da memória em diálogo com os ambientes digitais, pois mais do que novos ambientes tecnológicos também se observa uma (re)organização de relações e interações entre conglomerados de comunicação, produtos, processos e públicos. São camadas que necessitam ser exploradas para que se possam averiguar os efeitos do processo de arquivamento da memória audiovisual, bem como da digitalização de produtos desenvolvidos sob o aporte analógico. A ecologia das mídias assume a proposição de que "o meio é a mensagem", ou seja, o caminho (ambiente) pela qual esse conteúdo vai ser transmitido tem protagonismo no processo comunicacional:

\footnotetext{
A seção "o meio é a mensagem" pode, talvez, ser esclarecida salientando que qualquer tecnologia cria gradualmente um ambiente humano. Os ambientes não são embalagens passivas, mas processos ativos. [...] 'O meio é a mensagem' significa, em termos da era eletrônica, que um ambiente totalmente novo foi criado (MCLUHAN, 1964, p. 6-7, tradução e grifo nossos).
}

Tais ambientes são criados para propor uma ressignificação não somente das mas para as mídias, pois eles são vistos como "um entorno invisível que possibilita e condiciona comportamentos, relações, formas de pensar e de perceber o mundo" (DALL'AGNESE; BARICHELLO, 2017, p. 3). Uma vez que "toda nova tecnologia acarreta uma nova cultura e uma nova maneira de imaginar e uma nova maneira de se relacionar com as pessoas" (VILELA; NUNES, 2011, p. 7). 
De modo geral, compreende-se as ideias desses autores do seguinte modo: há novas formas de comunicação e interação sendo intensificadas, pois as transformações tecnológicas ao longo da história sempre podem ser identificadas. Porém, no atual estágio tanto tecnológico e digital, quanto da própria estrutura sociocultural, existem novos condicionamentos e reordenação das relações sociais.

Diante dessa perspectiva, o meio funciona ao realocar, readaptar e reconstruir a paisagem midiática, sobretudo quando se pensa na televisão e sua relação com os ambientes digitais. A televisão enfrentou diversos momentos de (re)configuração e (des)construção: da saída do ao vivo para o uso do videotape; da imagem em preto e branco para o colorida; do analógico para o digital; do diálogo e intercâmbio como a internet, redes sociais, diferentes telas, mobilidade, transmidiação; do surgimento de aplicativos digitais para a o arquivamento e disponibilização de seu acervo, produtos da grade televisiva e desenvolvimento de produtos nativos, os chamados "produtos originais" do novo meio de produção.

Mas, entremeado às transformações estruturais, tecnológicas e culturais da televisão os telespectadores também adentraram no bonde das mudanças, e se veem afetados por características como: a aceleração da vida cotidiana; artefatos e dispositivos tecnológicos que tornaram as atividades mais rápidas, como o microondas, fritadeiras elétricas, smartphones e tablets, e a própria internet. Esta última, sobretudo, acarreta numa mudança estrutural da relação entre o mundo da televisão e do telespectador, que agora não somente pode mas é mediado pelas tecnologias digitais, e de telespectador passou a ser também usuário.

Com isso, os "[...] meios e ambientes geram novas e variadas relações resultantes de sua natureza instável, móvel e global, gerando um constante estado de desequilíbrio que rapidamente se reequilibra para logo se desequilibrar novamente $[\ldots]$ ]" (CANAVILHAS, 2010, p. 2). E podem ser vistos sob dois ângulos: os meios como ambientes e os meios como espécies (SCOLARI, 2015). No primeiro, encontra-se a dimensão ambiental da ecologia midiática, podendo ser resumida pela ideia de que as tecnologias geram ambientes afetando os sujeitos que as utilizam, modelando sua percepção e cognição. Já a segunda percepção, 
por meio de um enfoque holístico, entende os meios como espécies que vivem em um mesmo ecossistema. Diante da primeira percepção é que se visualizam as transformações do universo televisivo e os pilares de discussão do artigo: memória, arquivamento e disponibilização on-line. No que se refere aos novos formatos de armazenamento, distribuição, mobilidade e acesso no contexto dos aplicativos digitais, como no caso do Globoplay, discutidos a seguir.

\section{Os lugares da memória e a permanência de uma relação com o passado}

O campo da memória tem sido vislumbrado por diferentes disciplinas, como a medicina, a filosofia, o jornalismo, a arquivologia entre tantas outras. Esses caminhos que a memória perpassa também dialogam com a história, a construção de identidades e o próprio ato de salvaguardar, armazenar e acessar o passado registrado. Como explicitam Oliveira, Rodrigues e Castro (2017) é possível definir a memória, de um modo genérico e amplo, como a capacidade humana de retenção de fatos e experiências do passado, que pode ser evocado e retransmitido para às novas gerações, a partir das funções psíquicas. Nessa mesma corrente de pensamento, Varella (2011) explica que a memória é a forma como o cérebro adquire e armazena informações, pois a memória funciona como essa capacidade do cérebro em adquirir, guardar e lembrar informações (IZQUIERDO, 2002), mas sendo difícil retê-las por um longo período.

Diante disso, a ideia de retenção está presente na proposta de lugares de memória estabelecida por Nora (1993). O autor expõe a perspectiva de que não havendo mais memória é preciso criá-la e logo se vale desses lugares (artificiais) para que seja possível a manutenção com o passado no tempo presente. Os lugares de memória, assim, estão situados nos restos das lembranças e representam "a forma extrema onde subsiste uma consciência comemorativa numa história que chama, porque ela [a memória] a ignora. É a desritualização de nosso mundo que faz aparecer a nação" (NORA, 1993, p. 12-13).

Os lugares de memória funcionam como a externalização e materialização dessas lembranças através de suportes e objetos como os arquivos (físicos ou digitais), 
pois essas lembranças não são naturais. Nelas encontram-se representações desses fragmentos de memória, capazes de fornecer subsídios para a relação do sujeito com o tempo passado. Com isso, a externalização da memória também é vista como um ato não natural.

Nossa memória tornou-se artificial quando um de nossos ancestrais, em um distante passado Neolítico, riscou uma pedra, gostou do que viu, riscou outras e perenizou os primeiros sinais indicativos de que ali estava em ação e habitando o mundo uma espécie animal que pretendia deixar marcas de sua existência que sobrevivessem ao artífice que as lavrava (PALACIOS, 2014, p. 89).

Dessa forma, compreende-se que a artificialidade da memória é um processo intrínseco ao ser humano, desde as pinturas rupestres aos meios convergentes e multiplataformas nos dias atuais, criando condições para essa externalização (MALDONADO, 2007). Nesses lugares artificiais e tecnológicos dos ambientes digitais é que se visualiza o surgimento desses lugares de memória, que "[...] podem funcionar como potencializadores da memória [...] mas que ainda são pouco explorados" (CAJAZEIRA; SOUZA, 2019, p. 1). Não são novos lugares cujos sentidos objetivam um ineditismo de uso para a memória, mas novos sob a lógica do uso com a função e intencionalidade de salvaguardar, arquivar para recuperar e disponibilizar. Uma mudança de pensamento e usabilidade que ainda necessita de melhores apontamentos, discussões e práticas.

Assim, com o uso de ferramentas, recursos e artefatos digitais os novos lugares de memória se entrelaçam com o advento da tecnologia digital, em que se observa o aumento da capacidade de armazenamento e processamento da expansão da memória para além do espaço físico. Isso implica um maior volume informacional, a necessidade de gerenciamento mais controlado e a informação disponível para acesso, pois o espaço digital é um "espaço virtualmente ilimitado para o armazenamento de informação que pode ser produzida, recuperada e associada à disponibilização dos públicos alvos visados" (PALACIOS, 2014, p. 95) e disseminada sem limitação de tempo e espaço. 
Diante desses novos lugares de memória, como arquivo, é que se visualiza o papel que as empresas de televisão estão desempenhando na contemporaneidade com a digitalização do seu acervo audiovisual. Algo que pode ser identificado com o surgimento do Globoplay e de novos modelos de negócio para a Rede Globo, que além de arquivar digitalmente esse acervo, em caráter parcialmente público (os conteúdos do aplicativo não estão todos disponíveis gratuitamente), também o monetiza.

\section{Modelo de negócios, práticas de arquivamento audiovisual e acesso à memória televisiva}

A seguir, a atenção é dada ao cenário das aplicações digitais com o desenvolvimento, fortalecimento e espalhamento dos aplicativos digitais em consonância com os dispositivos móveis e o uso estratégico da internet pelos diversos setores sociais. A discussão é centrada nas potencialidades do uso desses aplicativos pelas empresas de televisão, bem como empresas de serviços de streaming e Video on Demand (Vídeo sob Demanda), que tem sido popularizado no mundo. Empresas como Netflix, Amazon Prime, Hulu, Disney+, HBO Go, Crackle, Apple TV e Globoplay, no Brasil, fornecem serviços de streaming com foco em produtos audiovisuais sejam filmes, séries, documentários em caráter de reprodução (quando o conteúdo é apenas agregado e disponibilizado pelos serviços) ou em caráter inédito (quando o conteúdo é produzido e disponibilizado por essas plataformas). Inicialmente se destaca o caráter tecnológico e econômico com o surgimento desses serviços, funcionando como novo modelo de negócio em torno da produção e disponibilização de conteúdo audiovisual.

Em um segundo momento, entende-se que essas plataformas e serviços comportam uma dupla funcionalidade: um lugar de arquivamento e memória, presente em sintonia com a nova ecologia midiática e processos de crossmedia (distribuição do mesmo conteúdo em diversas mídias) e transmedia (criação de conteúdos diferentes para cada mídia sobre o mesmo tema), ou seja, novos modelos de negócio frente aos novos recursos da era digital advinda com a internet. Essa realidade está relacionada com a convergência tecnológica e ao novo fluxo 
"[...] de conteúdos através de múltiplas plataformas de mídia, à cooperação entre múltiplos mercados midiáticos e ao comportamento migratório dos públicos dos meios de comunicação, que vão a quase qualquer parte em busca das experiências de entretenimento que desejam" (JENKINS, 2009, p. 29).

Na perspectiva de novos modelos de negócio e diálogo entre a televisão e a internet o serviço de streaming do Grupo Globo, Globoplay, é visualizado como um dos poucos serviços e plataformas desse segmento. De acordo com informações disponibilizadas ${ }^{3}$, o Globoplay é uma plataforma digital com streaming de vídeos sob demanda criada e desenvolvida em 26 de outubro de 2015. Enquanto modelo de negócio ele se apresenta como mais um canal da empresa, que além de disponibilizar os conteúdos da TV aberta também oferta alguns produtos audiovisuais de outros canais do grupo a exemplo do Multishow e, a produção de conteúdos exclusivos como séries, programas e documentários para os assinantes do serviço. Antoniutti (2019, p. 11) destaca que:

\footnotetext{
A Rede Globo de televisão foi, e continua sendo, a maior emissora do Brasil, tornando- se a maior produtora de conteúdo e, consequentemente, líder de audiência entre as emissoras de canal aberto. O surgimento dos vídeos sob demanda em ambientes on-line e a criação de uma plataforma digital da emissora refletem uma série de questões que dizem respeito à produção, à distribuição e ao consumo do audiovisual no cenário contemporâneo.
}

Assim, assistir televisão na contemporaneidade já não compete ao ato de fixar-se no aparelho de TV ou zapear usando o controle remoto e trocar de emissora. O novo fluxo pode ocorrer mediante a situação de mobilidade do sujeito e ao uso das diferentes telas e seus tamanhos, bem como o foco pode não ser uma emissora de televisão, mas, sim, um serviço de streaming ou mesmo as categorias disponíveis (filmes, séries, documentários, desenhos animados, conteúdos originais ou rever aquela série que já foi finalizada na televisão). Não há apenas uma grade com horário fixo e pré-estabelecido. O acervo audiovisual 
está disponível 24 horas por dia, podendo ser pausado, escolher o tipo de áudio, o idioma da legenda, recomeçar ou continuar assistindo de onde parou noutro momento a escolha de cada usuário.

Como argumentado anteriormente, é a concepção desse lugar de memória enquanto arquivo que se objetiva visualizar como possibilidade de recuperação e disponibilização do produto audiovisual televisivo. Aplicado ao contexto mercadológico, essa cultura vislumbra uma maior abertura do contato com os produtos audiovisuais da TV no ambiente multiplataforma. Com isso, há também um estreitamento do vínculo do usuário/telespectador com a televisão e seus conteúdos, mas operacionalizado pelo reordenamento da lógica da internet, do digital, da mobilidade e do controle do sujeito. Desse modo, o arquivo audiovisual televisivo no ambiente multiplataforma é redimensionado, seja como um gigantesco banco de dados, de contato com produções audiovisuais que já não estão mais na grade televisiva, ou ainda como outra forma de assistir à televisão na contemporaneidade: fragmentada e sem a presença da temporalidade estabelecida e marcada pela lógica televisiva.

Diante dessa operacionalização é que o acesso à memória dos arquivos televisuais na internet é modificado. Para Machado (2006), nessa nova forma de organizar o volume informacional produzido (os produtos audiovisuais) há uma dependência da migração do conhecimento e a incorporação de diversas organizações para a web, estruturando-se e adequando-se ao formato das Bases de Dados (BDs). Ou seja, há uma transcodificação, seja em seu formato ou em sua plataforma (MANOVICH, 2001), reestruturando o acesso à memória que anteriormente era restrito a funcionários do Centro de Documentação (Cedoc) ou quando o material era solicitado por pesquisadores. Com a introdução do arquivamento em aplicativos como os já citados, visualiza-se uma maior abertura, ainda que não em caráter totalmente público, pois o Globoplay opera sob modelo híbrido: em uma parte o acesso é público e gratuito e, em outra, o modelo é o pay-per-view (pague para ver).

Os procedimentos metodológicos adotados no estudo consistem numa abordagem qualitativa com estratégia de pesquisa descritiva sobre o aplicativo 
digital Globoplay, identificando como ocorre esse arquivamento e a reconfiguração do acesso à memória televisiva na internet. De acordo com Gerhard e Silveira (2009) a pesquisa qualitativa se preocupa com o aprofundamento da compreensão de um objeto ou grupo, ao visualizar as inferências e interferências do fenômeno. Assim, permite ao pesquisador conhecer o que já foi estudado anteriormente e, com isso, fundamentar o corpo teórico-reflexivo acerca do objeto de estudo.

A investigação se caracteriza como descritiva, realizando uma observação sobre as diversas dimensões do objeto e, com isso, suscitando reflexões sobre ele. Para Richardson (2011), esse tipo de pesquisa tem como objetivo principal uma descrição sistemática de determinado fenômeno que se deseje investigar de modo objetivo e detalhado. Dessa forma, é possível refletir sobre o modo como esses produtos audiovisuais, originais da televisão, estão sendo arquivados no aplicativo. E, ainda, sobre como a sua estrutura está sendo remodelada por essa lógica do lugar da televisão em ambientes digitais móveis, com base no processo de arquivamento e memória audiovisual.

A plataforma de serviço de streaming de vídeos sob demanda do Grupo Globo, na qual se encontram diversas de suas produções audiovisuais (programas variados, reality shows, novelas, séries, filmes, musicais, humorísticos, infantis, documentários e telejornais). O seu desenvolvimento perpassa as transformações do cenário de produção e disponibilização de conteúdo audiovisual, a exemplo de outras empresas como Netflix, Amazon Prime, Hulu, Disney+, HBO Go, Crackle, Apple TV. Mas, sendo diferenciado por manter relação de proximidade com a televisão, diferentemente de outros serviços que funcionam de forma independente. O aplicativo compreende dois tipos de produtos: os que são produzidos pelas emissoras do Grupo Globo (Rede Globo de Televisão, Multishow, GNT) ou o catálogo de filmes, e os produtos originais (original Globoplay), como séries e documentários. Além disso, o acesso aos conteúdos também perpassa dois tipos de usuários: os não assinantes, com restrição de conteúdo, e os assinantes que mediante o sistema de pagamento mensal/anual têm acesso livre a todos os produtos disponíveis no serviço de streaming. 
Para os assinantes, portanto, é possível ter acesso a todos os conteúdos exclusivos, bem como a toda a programação, que pode ser acessada ao vivo ou através dos arquivos que estão na memória do aplicativo. Já para os não assinantes os conteúdos são mais restritos como, por exemplo, trechos de novelas ou de séries, ou seja, com uma limitação no acesso, visto que a ideia é propiciar uma experiência de uso para que ele se torne um assinante. O desenvolvimento do aplicativo funciona como uma forma de expansão do universo televisivo, com o processo de convergência tecnológica entre televisão, internet e mobilidade e, com isso, possibilidade de ressignificar sua presença e audiência.

\section{Análise e discussão dos resultados}

O Globoplay tem um caráter híbrido, com conteúdo transpostos, de um lado, e conteúdos produzidos originalmente para a plataforma de streaming, de outro. Ao transitar entre os universos crossmedia (distribuição de serviços, produtos e experiências por meio das diversas mídias e plataformas de comunicação) e transmedia (construção de universos e histórias em diversos ambientes, que se interligam ou mantém proximidade), o aplicativo se configura como uma das poucas iniciativas brasileiras no setor, fato que advindo do Grupo Globo não é necessariamente uma novidade, já que, ao longo da sua história, a emissora sempre demonstrou esse caráter de inovação, estando muitas vezes à frente dos concorrentes.

Ao refletir-se sobre o uso do aplicativo digital para arquivamento compreendese que a estratégia, inicialmente de transposição, era marcar presença nessa corrida tecnológica e de distribuição de produtos multiplataformas, uma vez que empresas como a Netflix já estavam adquirindo status e aceitação a partir de 2013, existindo desde 1997 nos Estados Unidos. Criada em 26 de abril de 1965, a Rede Globo possui um histórico de alta produtividade audiovisual, seja em caráter jornalístico ou entretenimento. Assim, produtos e conteúdos, em seu centro de arquivo, estavam disponíveis para serem utilizados mediante processos de digitalização, o que de fato vem acontecendo desde sua Globoplay. 
No catálogo do Globoplay temos horas de programação distribuídas nas seguintes categorias gerais: 1) Novelas; 2) Séries; 3) Cinema; 4) Infantil; 5) Humor; 6) Variedades; 7) Realities; 8) Música; 9) Documentários; 10) Jornalismo; 11) Esportes e; 12) Programas locais. Ao serem arquivados nessa nova plataforma, tem-se o estabelecimento de novas condições de acesso, uso e interação com as obras audiovisuais televisivas, seja como modelo de negócios ou prática de arquivamento da memória.

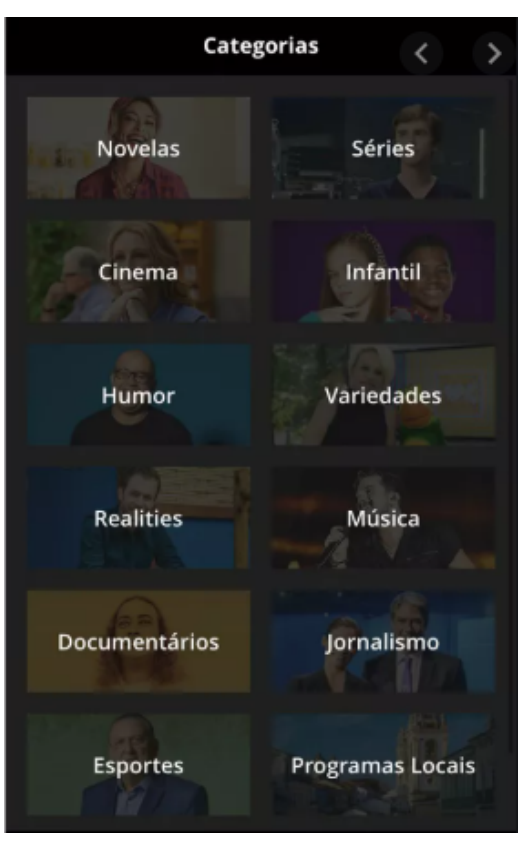

Figura 1. Visão geral do acervo no Globoplay pelo aplicativo digital Fonte: Printscreen da tela do aplicativo (2020).

As possibilidades do aplicativo, porém, ultrapassa um modelo de negócios, funcionando como plataforma tecnológica de arquivamento audiovisual da memória televisiva. Esses aplicativos digitais cujos serviços, primeiramente, são o streaming e a oferta de produtos audiovisuais, têm outra funcionalidade o arquivamento na internet. Esse caráter inovador é estratégico, sobretudo em relação ao Globoplay, pois ele mantém essa relação com sua emissora principal, a Rede Globo, para além da tela da TV - tanto as produções mais atuais quanto as mais antigas estão armazenadas no sistema de memória da empresa. Ou seja, o aplicativo também funciona como lugar dedicado à 
memória audiovisual. Recentemente, em meio à pandemia ocasionada pelo novo coronavírus, pela primeira vez telenovelas mais antigas ou que marcaram uma forte presença com a audiência chegaram ao catálogo, como Tieta (1989), Explode coração (1995), O rei do gado (1996), Por amor (1997), entre outras que estão sendo anunciadas, como Vale tudo (1988).

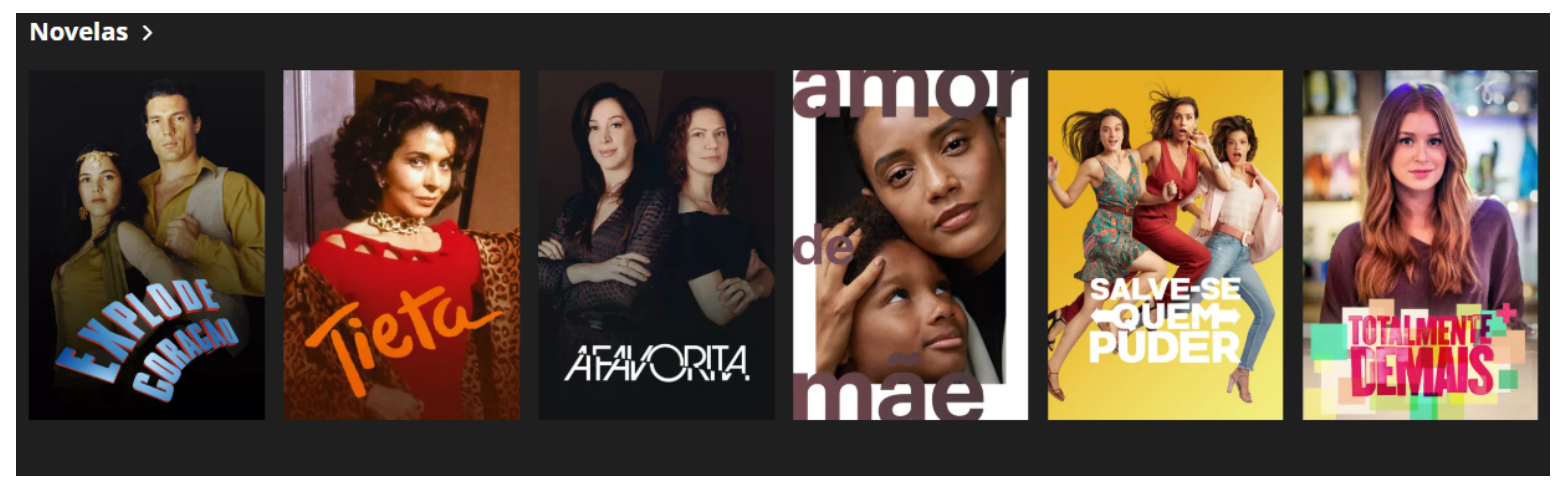

Figura 2. Catálogo de telenovelas no Globoplay.

Fonte: https://globoplay.globo.com/. Acesso em: 11 jul. 2020.

A partir do exemplo da digitalização das telenovelas para o aplicativo, apresenta-se na prática a questão do arquivamento nesse ambiente midiático digital. Um lugar de memória em sintonia com a expansão da territorialidade audiovisual sob as potencialidades da internet e do armazenamento on-line. O vínculo com a televisão é construído também por meio desse resgate de produtos audiovisuais que possuem um lugar marcante para os telespectadores, que agora têm uma plataforma digital móvel para isso. Com o Canal Viva servindo como lugar de memória para reprises de programas, telenovelas e demais produtos (mas sendo um canal pago) e o Vale a Pena Ver de Novo com reprises de telenovelas, em canal aberto, a estratégia de diálogo entre memória televisiva e público já ocorria, porém diferentemente do alcance que o aplicativo possui.

Os efeitos desse arquivamento e uso da memória televisiva já estão sendo percebidos pelo crescimento do número de assinantes, como informa o site Mobile Time em live (transmissão ao vivo) com Erick Bretas, diretor de produtos e serviços digitais da emissora. De acordo com o diretor, o número de usuários em 
um ano mais que dobrou, com 2,5 vezes mais assinantes de 2019 até o primeiro semestre de $2020^{4}$. Essa mudanças pode ter sido causada pela pandemia Covid19, o isolamento social e o aumento de $10 \%$ de usuários oriundos de SmartTVs (que passou de $37 \%$ para $47 \%$ ), como afirmou Bretas, já que o aplicativo do Globoplay está instalado nesse modelo de TV.

Outro exemplo que pode ser descrito diz respeito à produção $O$ auto da compadecida. O filme, originalmente produzido em 2000 , foi resgatado vinte anos depois, sendo atualizado, remasterizado e disponibilizado em um série de quatro episódios, primeiramente no Globoplay e posteriormente na televisão aberta.

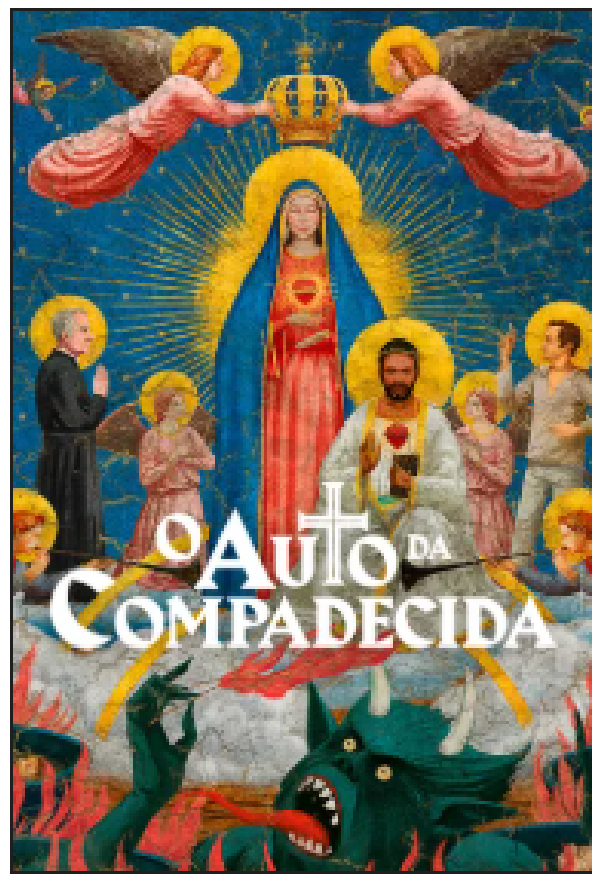

Figura 3. Série "O Auto da Compadecida" no Globoplay.

Fonte: https://globoplay.globo.com/busca/?q=compadecida. Acesso em: 11 jul. 2020

Com isso, identifica-se que a televisão, na era da cultura digital compreendendo a ubiquidade e a mobilidade - se desconstrói e se reconstrói constantemente com bases e ideais perpassando a multiplicidade das mídias existentes e a nova realidade das múltiplas telas, de ambientes multiplataformas, 
de lugares e horários não fixados no tempo-espaço. Ainda nesse ambiente, como estabelecido pela ecologia das mídias, o conteúdo não é o fundamental, mas os processos que estão envoltos no próprio ambiente. São as complexidades apresentadas que afetam a estrutura de interação, e de processos e fluxos de comunicação, que incidem diretamente nas percepções das organizações, como no caso do Grupo Globo.

Essas mudanças, adaptações e reconfigurações no contexto da ecologia midiática e das transformações tecnológicas reorganizam o sistema televisivo em seu processo de convergência com ambientes midiáticos digitais, não somente no âmbito técnico e tecnológico, mas cultural, econômico, simbólico, de relações pessoais e da memória. Nesse campo da memória o panorama ecológico das mídias possibilita a manutenção de laços com o audiovisual televisivo, encerrado, parcialmente, com o final da exibição de determinado programa na TV.

É nesse sentido que se pode pensar a ideia dos aplicativos digitais como um ambiente de informação e comunicação, que reestrutura a cadeia comunicacional e as formas de interação e arquivamento da memória do conteúdo televisivo. A televisão torna-se, nesse cenário, fragmentada por esses arquivos audiovisuais nesse aplicativo. Trata-se de uma biblioteca audiovisual, uma videoteca, mas na qual o serviço não funciona como um bem público, mas isso não torna a observação dessa realidade menos importante, pois o que se coloca em reflexão é exatamente o vislumbre desse e de outros aplicativos como lugares de memória. Dessa forma, é possível falar sobre TV-arquivo, TV-partícula, TV-fragmento, que deixa de ser vista por seu suporte e passa a ser ressignificada a partir dessa quebra do produto em pequenas células audiovisuais de acordo com o uso de cada usuário, pela sua interação com conteúdos nesses ambientes e condicionando uma nova forma de percepção de experiência audiovisual e audiência. No campo da memória, esse ecossistema midiático digital altera a forma como o armazenamento e o acesso ao conteúdo audiovisual televisivo ocorrem no âmbito da internet - seja pela via da empresa ou do telespectador/usuário. 


\section{Considerações finais}

Em conformidade com os objetivos traçados, identificou-se, primeiramente, a necessidade de ampliar a discussão sobre os processos de arquivamento audiovisual televisivo em ambientes digitais de informação. O recorte para o uso de plataformas de aplicativos digitais representa uma das possibilidades do estudo, no diálogo com o surgimento do novo ecossistema midiático.

Vislumbra-se que as plataformas dos aplicativos digitais, como no caso do Globoplay, mantêm uma relação que tanto propicia um novo modelo de negócios, como um novo lugar de acesso à memória audiovisual da TV. Contudo, é preciso destacar que por ser uma plataforma na qual é necessário realizar uma assinatura para acesso ao conteúdo integral, tem-se uma limitação de acesso e uso da memória. Isso pode servir de estímulo para que outras iniciativas em caráter aberto e público possam surgir nessa ecologia midiática da televisão e internet.

Nesse sentido, as potencialidades do Globoplay podem ser melhor identificadas e utilizadas, bem como outros exemplos podem tomá-lo como base para o desenvolvimento de plataformas em aplicativos digitais objetivando o arquivamento da memória televisiva. No Brasil, há um legado da TV diante de seus 70 anos de existência, dada a diversidade e a pluralidade de emissoras e conteúdos que guardam a memória da sociedade, da cultura, das transformações e das paisagens dos sujeitos. E que infelizmente permanecem, quase sempre, em centros de documentação, museus, empresas de mídias que não propiciam a digitalização e o compartilhamento digital dessas imagens como forma de rememoração do passado audiovisual.

\section{Referências}

ANTONIUTTI, C. L. Globo Play: um estudo sobre a plataforma de video on demand da Rede Globo. Paulus, São Paulo, v. 3, n. 6, jul.-dez. 2019. 
BRASIL. Secretaria Especial de Comunicação Social. Pesquisa brasileira de mídia 2016: hábitos de consumo de mídia pela população brasileira. Brasília: Secom, 2016.

CAJAZEIRA, P. E; SOUZA, J. J. G. A memória virtualizada do arquivo audiovisual jornalístico. In: Anais. Encontro Nacional de Pesquisa em Ciência da Informação, UFSC, 2019. Disponível em: https://conferencias.ufsc.br/index.php/enancib/2019/ paper/view/474. Acesso em: 28 jan. 2020.

CANAVILHAS, J. O novo ecossistema mediático. Biblioteca On-line de Ciências da Comunicação, 2010. Disponível em: http://www.bocc.ubi.pt/pag/canavilhasjoao-o-novo-ecossistema-mediatico.pdf. Acesso em: 6 fev. 2020.

DALL'AGNESE, C. T. W.; BARICHELLO, E. M. R. Media Ecology: abordagem contextual para o estudo das narrativas jornalísticas transmídia. In: Anais. Congresso de Ciências da Comunicação na Região Sul, UCS, 2017. Disponível em: http://portalintercom. org.br/anais/sul2017/resumos/R55-1307-1.pdf. Acesso em: 5 fev. 2020.

GERHARDT, T. E.; SILVEIRA, D. T. Métodos de pesquisa. Universidade Aberta do Brasil (UAB/UFRGS) e pelo Curso de Graduação Tecnológica. Porto Alegre: Editora UFRGS, 2009.

IZQUIERDO, I. Memória. Porto Alegre: Artmed, 2002.

JENKINS, H. Cultura da convergência. 2a. ed. São Paulo: Aleph, 2009.

JOST, F. Que relação com o tempo nos é prometida na era da ubiquidade televisiva. In: SERRA, P.; SÁ, S.; SOUZA FILHO, W. (orgs.). A televisão ubíqua. Covilhã, Portugal: UBI/LabCom, Livros LabCom, 2015.

LEVINSON, P. Cellphone. New York: Palgrave, 2004. 
LEMOS, A.; JOSGRILBERG, F. (orgs.). Comunicação e mobilidade: aspectos socioculturais das tecnologias móveis de comunicação no Brasil. Salvador: EDUFBA, 2009.

MACHADO, E. O jornalismo digital em base de dados. Florianópolis: Calandra, 2006.

MALDONADO, T. Memoria y conocimiento: sobre los destinos del saber en la perspectiva digital. Barcelona: Gedisa, 2007.

MANOVICH, L. El lenguage de los nuevos medios de comunicación. Cambridge: MIT, 2001.

MCLUHAN, M. Understanding media. New York: McGraw-Hill, 1964.

NORA, P. Entre memória e história: a problemática dos lugares. Revista Projeto História, v. 10, jul.-dez., 1993. Disponível em: https://revistas.pucsp.br/revph/ article/view/12101/8763. Acesso em: 9 abr. 2020.

OLIVEIRA, E. B.; RODRIGUES, G. M.; CASTRO, R. M. A memória na ciência da informação: uma análise da produção científica brasileira. In: OLIVEIRA, E. B.; RODRIGUES, G. M. (org.). Memória: interfaces no campo da informação. Brasília: Editora UnB, 2017.

PALACIOS, M. Jornalismo, memória e história na era digital. In: CANAVILHAS, J. (org.). Webjornalismo: sete características que marcam a diferença. Covilhã, Portugal: UBI/LabCom, Livros LabCom, 2014.

POSTMAN, N. Tecnopólio: a rendição da cultura à tecnologia. São Paulo, Nobel, 1994.

RICHARDSON, R. J. Pesquisa social: métodos e técnicas. 3a. ed. São Paulo: Atlas, 2011. 
ROSSINI, M. S.; SILVA, A. R. Do audiovisual às audiovisualidades: convergência e dispersão nas mídias. Porto Alegre: Asterisco, 2009.

SERRA, P.; SÁ, S.; SOUZA FILHO, W. (orgs.). A televisão ubíqua. Covilhã, Portugal: UBI/LabCom, Livros LabCom, 2015.

SCOLARI, C. Ecología de los médios: entornos, evoluciones e interpretaciones. Barcelona: Gedisa, 2015.

SOUZA, J. J. G.; CAJAZEIRA, P. E. S. L. Cultura do arquivamento audiovisual: armazenamento, acesso e recuperação da informação em ambientes digitais. Ci. Inf. Rev., v. 7, n. 1, jan./abr., 2020. Disponível em: http://www.seer.ufal.br/ index.php/cir/article/view/9529. Acesso em: 10 jun. 2020.

VARELLA, D. Memória. Entrevista ao site UOL, 25 mar. 2011. Disponível em: https:// drauziovarella.uol.com.br/corpo-humano/memoria/. Acesso em: 20 jan. 2020.

VILELA, M. D.; NUNES, A. C. Entrevista com Eric McLuhan. Sessões do Imaginário, ano 16, n. 26, 2011.

Submetido em: 10 fev. 20 | aprovado em: 12 ago. 20 